\title{
COMMUNITY OF ASSESSMENT PRACTICE OR INTERESTS\& THE CASE OF EAP WRITING ASSESSMENT
}

\author{
Faisal Al-Maamari \\ Deputy Director for Professional Development \& Community Service \\ The Language Centre, Sultan Qaboos University \\ faisalf@squ.edu.om
}

First received: 3 April 2015

Final proof received: 22 Januari 2016

\begin{abstract}
Setting, disseminating and applying assessment standards are part of university academic programmes of study. Nowadays, assessment is increasingly viewed from a social practice perspective, and so doing entails exploring how the quality of assessment is shaped by interaction and co-participation with different communities of practice. Therefore, based on this perspective, the study reported here aimed to examine the assessment policies and practices of laboratory report writing of first year students in credit-bearing, English for Special Purposes programmes at a university in the Sultanate of Oman. Interviews of programme administrators and the instructors plus institutional and programme documents were examined to investigate these assessment policies and practices. The programme administrators were asked about how they planned the written assessment in their programmes, and the instructors were asked about their experiences of these assessments. The data were then analysed thematically using community of practice framework, namely in relation to (1) a shared repertoire of communal resources, (2) mutual engagement, and (3) a sense of joint enterprise. It was found that instead of community of practice, there were (sub)communities of practices wherein interaction, negotiation and communication amongst members and non-members were punctuated by control, power and autonomy, all working with the aim of narrowing the range between the personal goals of the academic and the communal goals of the institution. The overarching conclusion is that in their assessment practices, the two instructional programmes exhibited varying degrees of community of practice based on the above three attributes.
\end{abstract}

Keywords: Assessment standards, community of practice, laboratory report, Oman EAP

Setting, disseminating and applying assessment standards are part of university academic programmes of study. Studies focusing on the causes of inconsistency amongst assessors are increasingly gaining popularity in general educational research (e.g., Hunter \& Docherty, 2011; Price et al., 2011; Shay, 2008) and in language education (see Barkaoui, 2011). These researchers have to date highlighted different factors leading to inconsistency in awarding assessment scores such as ambiguous modes of assessment or assessment criteria (O’Donovan, Price \& Rust, 2004), the absence of disciplinary knowledge as anchorage point for our assessment processes (Shay, 2008; Price, 2005), the effect of tacit beliefs (Hunter $\&$ Docherty, 2011) and marking method and rater experience (Barkaoui, 2011).

More recently, however, assessment is increasingly considered a form of social practice; this means that psychometric properties of testing (validity, reliability) are not enough; our conceptions of knowledge have moved our understandings of assessment from the positivist philosophy where knowledge is seen as monolithic and atomic to social constructionist philosophy where knowledge is context-bound and situated (O'Donovan, Price \& Rust, 2004). Therefore, in order to make our assessment reliable, understanding of assessment standards requires all involved in the assessment process to reach consensus on as well as share both explicit and tacit knowledge and beliefs. How this can best be done is not well-understood. The setting of standards alone is not sufficient to achieve consistency and alignment amongst different assessors. Further, making assessment marking guides more explicit as opposed to implicit (Hunter \& Docherty, 2011; O’Donovan, Price \& Rust, 2004) is necessary yet insufficient.

Recently, researching assessment practices from social constructionist theory namely community of practice has begun though still little is written on educational and language assessment from this perspective. The only study which explicitly approaches educational assessment from community of practice is that conducted by Price (2005). Price examined the assessment practices in university business modules and found no sense of participation in the setting, sharing and implementation of assessment standards. However, it is not clear the conditions which facilitate reliable assessment amongst university instructors from a community of practice perspective. More recently, Price et al. (2011) set out 10 premises for good assessment practice. In Premise 7, they state that 
assessment standards reside in academic/ professional communities (p. 6). The extent to which this residence and its characteristics are evident in the assessment of writing of first year students in two English for Special Purposes programmes in a university setting is explored in this paper using the community of practice framework.

The assessment of laboratory report writing was specifically examined in these ESP programmes of study for two reasons. Firstly, the importance of the technical laboratory report writing is evident in its status as the 'default genre' for assessing learning and competence in science classes in higher education. Secondly, in this genre, both disciplinary content and language aspects are the focus of the assessment as compared to other generic writing assessments such as essays or exam papers where language only issues are paramount.

\section{LITERATURE REVIEW}

In situated learning theory, knowledge-building and learning in a community of practice (CoP) are context-dependent, experiential, and sociallyembedded in the group's practices (Huzzard, 2004). Lave and Wenger (1991) saw a CoP as "an intrinsic condition for the existence of knowledge" (p. 98) where co-participation and social relationships based on activity are key to developing communities. Central to community of practice in its conceptualization of knowledge is the concept of legitimate peripheral participation, which indicates that "learning is embedded in power relations and processes of identity formation" (Huzzard, 2004, p. 352). However, amongst the criticisms levelled at the theory in the literature is its ignorance of issues of power, which have not been sufficiently theorized in discussions of learning and practice (see review by Cox, 2005; Fox, 2000; Huzzard, 2004; Roberts, 2006). For example, it has been pointed out that in the cases discussed in the literature the only form in which power was apparent is in the apprentice's movement in knowledge-building and learning from novice to expert. In sum, the negotiation of knowledge transfer and sharing has been more harmonious than conflictual (Roberts, 2006).

Wenger et al. (2002) defined a CoP as a "group of people who share a concern, a set of problems, or a passion about a topic, and who deepen their knowledge and expertise in the area by interacting on an ongoing basis" (p. 7). Wenger (2000) lists three attributes of successful communities of practice. These are (1) a shared repertoire of communal resources, (2) mutual engagement, and (3) a sense of joint enterprise. In (1), members produce and compile a set of items, languages, tools, stories, "and other explicit artefacts as well as various implicit relations, tacit conventions, and underlying assumptions and values" (Handley et al.,
2006, p. 645). In (2), community members develop and engage with each other through norms, relationships and regular interaction, and in so doing broaden and deepen their knowledge base. In (3), members seek and share common aims and joint purposes which help them to reach common understandings amongst themselves.

The notion that "the unusual demarcation between university goals and personal goals" weakens the take of community of practice in academe (Nagy \& Burch 2009, p. 242) may be explained using power relations. Nagy and Burch elicited differences between corporations and academe in power relations in terms of structure and freedom. They maintain that whilst in corporations power structures are well defined, those existing in academe are poorly defined. Further, in academe employees have significant freedom to individualize their personal objectives in relation to the organizational objectives. In corporations employees have little freedom to privatize or pursue their personal objectives. However, there is still little empirical research in this area; what is new about the current study is that it aims to bridge this gap in the literature though putting community of practice to the test in the assessment of EAP writing.

In her study, Price (2005) found that setting standards was the responsibility of the module leader, and that these standards were presented as non-negotiable. In sharing standards, it was found that the module leaders depended more on strategies which convey explicit rather than implicit knowledge, the latter of which is thought more transferable through socialization processes. In briefing sessions, questions, when asked, concentrated on techniques of marking and grade penalties rather than the explicit discussion of or engagement in tacit knowledge and beliefs about the assessment task/standards or about disciplinary knowledge (Shay, 2008). In applying the standards, a sampling approach rather than a double-marking approach was employed, thus reducing opportunities for assessor involvement. These all indicate that participation was not a major activity in the context.

Whilst the study by Price (2005) sheds light on the theory of community of practice in exam tasks as a form of summative assessment, the study reported here sheds parallel light on the assessment of one specific type of scientific and technical writing, the laboratory report. In this data-based study of EAP writing assessment as a case, the performance of two programmes as evidenced by the practices of the programme leaders and the instructors is assessed to the extent that they demonstrate evidence of the three attributes presented by Wenger (2000) as reviewed at the outset. The paper draws on descriptive data primarily from instructor interviews, and has been guided by the following two research questions: (1) How do the programme leaders plan the laboratory 
report writing assessment in their programmes? and (2) How do the instructors view the laboratory report writing assessment in these programmes?

\section{METHODOLOGY}

\section{Participants}

A total of 9 instructors agreed to take part in the study. Six came from one programme (thus, Programme 1), and the other 3 came from the second programme (Programme 2). Potential participants were identified by the researcher at the initial stages of data collection. Their demographic characteristics appear in Table 1.

The instructors are TEFL qualified teachers, who come from 'Centre' and 'Periphery' countries (Kachru, 1997), or participants from English and non-English speaking countries. All participants have Bachelors \& Masters in general English language teaching. Further, the sample also differs with respect to teaching experience across contexts (general TEFL and specific domain) and programmes (1 \& 2).

Table 1. Research participants' demographic characteristics

\begin{tabular}{|c|c|c|c|}
\hline Programmes & Pseudonym & $\begin{array}{c}\text { Years of } \\
\text { teaching at ELC-TEFL }\end{array}$ & $\begin{array}{l}\text { Years of teaching at current } \\
\text { programme-Specific Domain }\end{array}$ \\
\hline \multirow{6}{*}{ Programme 1} & P1L & 5 & 2 \\
\hline & P1T1 & 16 & 13 \\
\hline & P1T2 & 8 & 3 \\
\hline & P1T3 & 17.5 & 2.5 \\
\hline & P1T4 & 5 & 2 \\
\hline & P1T5 & 7.5 & 0.5 (1 semester) \\
\hline \multirow{3}{*}{ Programme 2} & P2L & 10 & 5 \\
\hline & P2T1 & 5 & 3 \\
\hline & P2T2 & 2.5 & 1.5 \\
\hline
\end{tabular}

P1=Programme 1; P2=Programme 2; T=teacher; PL=Programme Leader

For general TEFL teaching experience, the median $^{1}$ for $\mathrm{P} 1 \quad \& \quad \mathrm{P} 2$ is 7.75 and 5 years respectively; for domain specific teaching experience it is 2.25 and 3 years respectively. Overall, it is clear the significantly little content, domain-specific knowledge/ experience the instructors possessed.

\section{Instruments}

Semi-structured interviews were primarily used to answer the research questions. Whilst the interview themes remained constant, alterations in questioning (e.g., asking follow-up questions) were allowed to vary according to the unique context of each interview. For example, the programme administrators (i.e. leaders) were asked about how they planned laboratory report writing assessment tasks of their students, and the instructors were asked about how they viewed the contents and methods of these assessments. The interviews took an average of 45 minutes, and were all conducted in English. The interview schedule focused on the following themes:

- Overall description of assessment in instructional programme

- Overview and description of assessment tasks

- $\quad$ Rationale for the quantity and type of assessment

- Participation in the assessment design and requirements for such participation
- $\quad$ Sources of knowledge about assessment/assessing

The interviews allowed the participants to have the opportunity to talk about the instructional programmes' effectiveness to prepare students for their academic studies and about the appropriateness of the assessment tasks at the intersection between language and subject matter. Further, the participants were asked about their understandings of the assessment tasks, and their views of the marking systems and the assessment materials. All participants contacted for this research accepted to participate. The participants were promised anonymity as part of the research ethics, and so generic codes are used in this paper.

To provide a more complete account of the assessment practices in the two instructional programmes and to further increase confidence in the credibility of the findings, the emergent data from the interviews were triangulated using programme and institutional assessment documents. During this time, I had access to all assessment materials, assessment tasks, marking systems, and students' marked scripts. I was a language instructor in one of the researched programmes a number of years prior to data collection, and so I was familiar with the subject matter requirements in teaching and assessing the laboratory report, and possessed high degrees of knowledge about and interest in the relevant disciplinary domain.

Researched instructional programmes

The study took place in an English language centre 
(ELC) in a university in Oman. The ELC offers both foundation (pre-sessional and non-credit-bearing) and non-foundation (in-sessional and credit bearing) English language programmes for first year students. The two sampled credit programmes are part of the degree programme taken by first year students aiming for a Bachelor of Science (BSc) qualification. These programmes aim to equip undergraduate students with the language and academic skills to enable them to complete their studies successfully. The programmes in question aimed to develop the students' reading and technical writing skills, and the laboratory report writing assessment was a major component in both. The assessment of the laboratory report required teachers to assess language (i.e. vocabulary, structure and style), rhetorical organisation (objectives, procedure, results, etc.,) and subject-matter knowledge.

\section{Data analysis}

Given the two instructional programmes, the analysis was done through a cross-case strategy (Miles \& Huberman, 1994). Initially, the data were coded inductively over a long period of time and that involved writing codes, or grouped chunks of data, and then building up (sub)categories. This process allowed for the identification of recurrent similar and contrasting attributes within/across the two instructional programmes.

The choice of a theoretical framework to explain the data was not a straightforward process. The community of practice framework was not $a$ priori determined. Instead, it was brought to bear on the emergent themes in the later stages of the analysis in order to examine the fit between the assessment practices of the two instructional programmes and this framework. In the initial thematic classification, issues of power relations were not prominent. At that stage, the qualitative analysis revealed three major factors (see Table 2) describing the assessment practices of the instructors in these programmes. These are (a) understandings of programme curriculum objectives vs. instructor personal constructions, (b) facilitation of access to knowledge of assessment subject matter, and (c) search for subject matter knowledge of assessment.

Table 2. Main factors/themes resulting from the analysis

\begin{tabular}{lll}
\hline \multicolumn{1}{c}{\begin{tabular}{c}
\multicolumn{1}{c}{ Programme } \\
Themes
\end{tabular}} & \multicolumn{1}{c}{ Programme 1 } & \multicolumn{1}{c}{ Programme 2 } \\
\hline $\begin{array}{l}\text { Programme goals } \\
\text { vs. Personal } \\
\text { constructions }\end{array}$ & $\begin{array}{l}\text { Diverse constructions of programme } \\
\text { objectives and subject-matter of } \\
\text { assessment because of different } \\
\text { meanings/emphases in the assessment } \\
\text { tasks, marking systems and the textbook. } \\
\text { Meanings and curricular emphases are } \\
\text { distributed } \text { across the assessment tasks, } \\
\text { marking systems, and the textbook. }\end{array}$ & $\begin{array}{l}\text { The programme goals including purposes } \\
\text { of assessment are generally unified, and } \\
\text { do not differ from instructor } \\
\text { constructions. } \\
\text { Meanings and curricular emphases are } \\
\text { well-controlled } \text { across the assessment } \\
\text { task, marking system, and the textbook. }\end{array}$ \\
\hline $\begin{array}{l}\text { Facilitation of } \\
\text { access to knowledge } \\
\text { of assessment } \\
\text { content }\end{array}$ & $-\begin{array}{l}\text { Little is done to facilitate access of } \\
\text { knowledge about assessment content and } \\
\text { procedures to instructors. } \\
\text { Limited } \text { access to design of assessment } \\
\text { tasks and procedures. These are } \\
\text { exclusively carried out by the } \\
\text { programme leader. }\end{array}$ & $\begin{array}{l}\text { A little is done to facilitate access of } \\
\text { knowledge about assessment content and } \\
\text { procedures. } \\
\text { Limited access to design of assessment } \\
\text { tasks and procedures. These are } \\
\text { exclusively carried out by the programme } \\
\text { leader. However, instructors were briefed } \\
\text { about concepts/constructs in the } \\
\text { assessment }\end{array}$ \\
\hline $\begin{array}{l}\text { Search for } \\
\text { assessment } \\
\text { knowledge }\end{array}$ & $\begin{array}{l}\text { Search for content of assessment is } \\
\text { individually done, is based on coalitional } \\
\text { groupings, and is transactional. }\end{array}$ & $\begin{array}{l}\text { Sharing of assessment procedures/content } \\
\text { is done in pairs/groups, is dialogical and } \\
\text { is interactional. }\end{array}$ \\
\hline
\end{tabular}

Subsequently, when issues of power became more central after further analyses and re-reading of the data, I decided to use the community of practice framework to foreground different facets of this perspective and to assess its transferability to the context under research.

The validity (trustworthiness) of the analyses was ensured through triangulation of methods, systematic analyses, and discussion of analyses and findings with colleagues (Creswell, 2009; Lincoln \& Guba, 1985). Because a cross-case study approach is used, generalisability (or transferability) of the research findings is seen as a "possibility" (Lincoln
\& Guba, 1985, p. 316) where it is reader-determined

based on the success of this research to reveal "the experience as a process" (Denzin, 1989, p. 505). This means that readers of this research are encouraged to determine which issues are particular to the context researched, and which ones may transfer to their own context.

\section{FINDINGS}

The findings are presented according to emergent themes as summarized in Table 2 above. Such 
tabulation offers a cross-comparison between the two instructional programmes vis-a-vis the three emergent themes.

\section{Assessment objectives: Programme vs. personal}

The interviews with the instructors revealed their perceptions of assessing the laboratory report on two planes: programme and personal. This enabled me to compare the constructions made by the instructors of the assessed construct (personal) and those provided in the taught textbook and the assessments (programme). In Programme 1, the analysis revealed different understandings of the goals of the programme and the aims of assessment amongst the instructors. Two major groups appeared in having a polarized understanding of the aims of the assessments. Three instructors in the programme operated from the curriculum, and saw that the assessment of the laboratory report should follow from what was taught and emphasized in the textbook. Hence, these instructors penalized students if they did not follow the genre of the laboratory report as outlined in the textbook:

\begin{abstract}
"the kind of students we get in science are more focused on numeracy, and so perhaps we should tailor the course so that those skills of report writing such as analyzing data and writing discussions of results are really developed". [P1T1]
\end{abstract}

The instructors in the second group ( 3 in total) saw that the students did not need to take the calculations in the assessment paper seriously and that a mere superficial discussion of the results, however erroneous, should be acceptable for language practice purposes. They maintained that language rather than the scientific subject matter was the major focus of the programme:

\begin{abstract}
"our students don't get very much practice in rewriting ... I still feel it can be simpler, like I feel we need to start them off, that's what I feel, with sentences like 'pick this sentence and rewrite it' as opposed to 'take this paragraph and re-rewrite it". [P1T4]
\end{abstract}

This disjuncture was less evident in Programme 2. In this programme, the assessment was tied closely to the planned curriculum, and this was due to the programme leader's tight control of genre to be assessed (i.e., in the sense of presentation of only one formulaic structure in the curriculum). Therefore, the instructors expressed a unanimous view of the assessment, and they displayed a general consensus on the nature of the task and how to assess both content and language.

Additionally, the instructors in both programmes were asked about the frequency of meetings to discuss assessment matters. Generally speaking, the instructors in both programmes noted the shortage of meetings and stated that more email rather than face to face communication was common. Instructors in Programme 1 especially complained about shortages in meetings and they did not see the use of electronic mail as an alternative to "getting together" (P1T2). In Programme 1, there was no discussion of the test paper prior to the assessment; on the other hand, in Programme 2, the test paper was given to the instructors beforehand, and a discussion of this test paper was carried out. Although the discussion here was very brief and was not focused on the actual contents of the assessment or the meanings of the constructs of the assessment marking system, it nevertheless addressed the suitability of the format and the difficulty level of the assessment paper. This allowed the instructors opportunity to comment on other related issues such as marks breakdown, and it further allowed them to see the connection between what they taught the students, and how the students were going to be assessed.

At the time of assessing the laboratory report, a double marking approach was taken in both programmes. During the meeting in which the assessment/test was discussed, Programme 2 instructors were paired for double-marking. However, in Programme 1 because the instructors often operated from different conceptions of the genre, and marked according to what they believed should be marked, they resorted to selecting markers with the same orientations, and understandings of the goals and requirements of the assessments. During interviews, programme 1 instructors clearly voiced their concerns about the knowledge required to assess the laboratory reports. They therefore specifically requested scientific content guides and discussion of the requirements of these guides so that they were able to assess properly. One instructor (P1T5) stated that he/she had to do his/her "homework" by knowing scientific laws such as "Newton's third law" and "Hooke's law". The scientific guide was needed so that both instructors and students were well aware of the expectations as required in fulfilling the requirements of writing laboratory reports:
"it could be marking criteria which could be given to instructors to enable them to understand what is expected from them and what is expected from their students as well when doing a lab report". [P1T2]

Therefore, with the absence of discussion on marking systems and the content requirements of the assessment tasks, the instructors in Programme 1 faced great difficulty. Here is one incident reconstructed from the interviews as recounted by one of the programme instructors. P1T2 had this conversation that went between him and a few of his students who paid a visit to his office: 
Students: Well the other students in the other class were not asked to do things that you asked us to do. I think you're asking us to do so many things.

P1T2: But these things are there in the hand-out. Students: The other instructors said that these things are not really important. Maybe these things are really complicated for you

Probed further, P1T2 explained that this conversation pertained to the requirements of the laboratory report relating to producing a Discussion of Results based on statistical information about the means and the standard deviations of a set of measurements on hands' length and circumference (the word 'things' above). His students receiving news that other instructors were setting different requirements for their students had a proposal to make to him: to allow them to carry out a "superficial comparison" of the results. It is clear that the students' fulfilment of these assignments (this was also ascertained from examining the students' reports where two distinct requirements appeared) was framed not by the planned curriculum, but by the compromises which they thought the instructors might have been operating in.

\section{Assessment design: Access vs. non-access}

Assessment design refers to the planning and the creation of the actual assessment tasks, and access refers to the programme leaders' willingness to allow his/her instructors to enter in the process of designing particular assessments or at least to involve them in aspects of it. The leaders of the two programmes were similar in that they were the ones who created the assessment tasks and in not allowing the instructors to take part in this activity; however, programme 2 leader differed in that she attempted to introduce her instructors to important concepts relating to the assessment of the laboratory report. From the interviews, it was apparent that what added to the difficulty of assessing the laboratory reports for the instructors in both programmes was the programme leaders' themselves setting varying constraints in front of the instructors to participate in the creation of the assessment of the laboratory report. In Programme 1 , the leader put the requirements for designing assessment based on the laboratory reports succinctly yet distinctly by stating the difficulty for the instructors to do so:

It's not easy to come up with assessments of the laboratory report. It's necessary for someone to have taught the course and to have a feel for the report writing before trying to design assessments based on the writing. [PIL]

The programme leader's view of the need for instructors "to have taught the course" and "to have a feel for the report writing" as prerequisites to designing assessment based on the laboratory report prevented the instructors form participating in this domain.

In Programme 2, aware of her own difficulty with laboratory report writing assessment, the programme leader narrated her entry into how she herself learned to tame this area for inclusion in the curriculum. The programme leader told of her learned confidence to design assessment based on the laboratory reports. She for example related how for a long time she just "used the old materials" that she inherited for teaching and assessment purposes. She gave three reasons why she kept using the old materials: (1) the fact that there was not "much change over the instructors on the course", (2) the fact that "there were two or three instructors who had been on the programme for a long time, and used those materials", and most importantly (3) the fact she "didn't know much about it, and it's only sort of more recently that [she has] felt confident to change it". Gaining more confidence, the programme leader worked to help her instructors particularly new ones to gain entry into this domain. Upon request by the instructors, the programme leader made use of written strategies rather than discussions to facilitate this. She for example made sure that she let them 'preview quizzes and let them see examples of students' work' en-route to making sure that they were "teaching things like the laboratory report in the same way that have been sort of established within the course" especially as she perceived the new instructors to "maybe have less of a science background".

Further, in addition to the programme leader's provision of old quizzes and examples of students' work to orientate the new instructors to the requirements of teaching and assessing the laboratory reports as requested, she also was

trying to make sure through the textbooks and test guides that even incoming new instructors know about concepts like controls and variables and such like. [P2L]

How the laboratory reports' teaching and assessment were perceived in relation to incoming new instructors in the programme by $\mathrm{P} 2 \mathrm{~L}$ was central to her work. Although the strategies employed by $\mathrm{P} 2 \mathrm{~L}$ were only as effective as transferring explicit knowledge (signalled by the word 'know about' in the excerpt), and the understandings held by the programme leaders of the contents of the laboratory reports are tacit, during interviews the instructors appreciated their being inducted into some aspects of the assessment. Judging by the framework proposed by O'Donovan, Price and Rust (2004) for the transfer of both explicit and implicit assessment knowledge, we can conclude that the strategies used by the programme leaders leant heavily towards those strategies conducive to the transfer of explicit knowledge. 
Also, the very few strategies which were evident in the assessment practices of the programme concentrated in the pre-assessment stage (e.g., marking systems) rather than during assessing (e.g., marking scripts).

On the whole, the programme leaders utilized written and transactional (i.e. through electronic email and the textbook) rather than oral or social strategies to transmit to their instructors the experiential and formal assessment knowledge which they themselves either acquired or learned. These transactional rather than interactional strategies stopped at appending written notes about important concepts and terminology used in experiments and in report writing to the textbook. It is clear however that on a few occasions programme 2 the leader tried to go beyond that in some cases and establish dialogue about specific content knowledge especially with new instructors who appreciated being included in this dialogue.

\section{Search for assessment content: Interactional vs. transactional}

In addition to the earlier area which explored what the leaders did to address the gap their instructors faced with the specific content knowledge, the interview data were further explored for the means to which the instructors across the two programmes resorted in order to fill this gap. This way, the research aimed to address the gap by examining the agency of both the programme leaders (in the section above) and the agency of the programme instructors (this section). During the interviews, the instructors in both programmes determined to provide the best learning opportunity for their students, and so they were encouraged/forced to go on search for this knowledge and communicate it to their students. The search for subject matter knowledge to help in assessment purposes was done differently across programmes. In Programme 2, the knowledge sharing of assessment was uncommon, but when it took place it was dialogic. One incident took place during class substitution which illustrates the beginning of legitimate peripheral participation for a new instructor. In that instance, P2T1, who had been teaching in the programme for three years, suggested that the 'best' practice in an informal, inclass assessment session on the laboratory report was for the new instructor to ask students to perform the task collectively:

\section{It so happened that one day that she couldn't make it to class, and so her class came and sat along with mine, and we did a lab report writing together, and they found it a VERY big difference, and they also went back to her, and they reported to her that they found it very different [P2T1]}

Indeed, the knowledge-sharing from the member (P2T1) to the non-member was completed in two further stations. First, the students "reported" this "innovative" technique to their instructor. Second, P2T1shared other relevant "stuff" supposedly after the 'new' instructor contacted him as follows:

So then, I gave this instructor all MY lab reports, and my unit notes, and stuff and I'm sure that would've helped her. [P2T1]

Here, being a member of the community with good possession of experiential knowledge about the laboratory reports by virtue of his three years' teaching experience in the programme, P2T1 aimed to share both knowledge of method of assessing the laboratory reports and tools (i.e. his laboratory reports and unit notes), which he was certain would have helped the new member dip into the practices of this community. This was done to facilitate the assessment process for the new instructor.

Whilst with the instructors in Programme 2 the search for knowledge was dialogic between two professionals alike, with the instructors in Programme 1 this took an individualistic route. Two instructors (P1T4 \& P1T5) looked to fulfil this gap (i.e. subject matter knowledge required for assessing the laboratory reports) by further closing themselves off through consulting with the Internet rather than with the programme leader or other instructors. One of these instructors recounted:

The other day a student queried something in the book and he said 'is this correct?' and he was quite sure. So I went to the Internet that evening and I checked, and he was actually right, so I then had to go back 'Hang on. This is in the book, and this is wrong'. [P1T5]

Further, with 13 years of teaching in this programme under her disposal, $\mathrm{P} 1 \mathrm{~T} 4$ did not resort to the programme leader for support. Instead, throughout the semester she utilised a blog to communicate with her students, providing them with guides on report writing assessment, practice exercises, and subject matter information every step of the way. P1T4 further introduced the marking system earlier to her students, and discussed the requirements of the system and how it fitted with the laboratory report writing assessment tasks.

In one sense, the use of these dialogic (i.e. P2), non-dialogic or outside-programme aids (i.e. P1) to share assessment knowledge and understanding can be paradoxically thought of as instructors creating or participating in other (existing) communities of practice, which they believe are valuable because they allowed them to see that their knowledge can be both accessible to and valued by their students.

\section{DISCUSSION}

The research was able to capture two major themes which had a bearing on instructors' assessment knowledge and understandings: (1) the 
predominance of personal curricular constructions over collective curricular objectives, and (2) the coexistence of power evidenced in the total control of assessment task design by programme leaders, and agency in the search by faculty for subject matter knowledge. Wenger (2000) lists three attributes of successful communities of practice. With very few notable exceptions, the research evidence does not suggest a strong difference between the assessment practices of the two instructional programmes as documented by this research and these three attributes: (1) a shared repertoire of communal resources, (2) mutual engagement, and (3) a sense of joint enterprise. The present research managed to model these attributes to the emerging analyses of the assessment practices in the two programmes (Table 3).

Table 3. Model relating the two instructional programmes vis-a-vis community of assessment practice as analytical framework

\begin{tabular}{|c|c|c|}
\hline $\begin{array}{c}\text { Programme } \\
\text { Attributes }\end{array}$ & Programme 1 & Programme 2 \\
\hline $\begin{array}{l}\text { Shared repertoire of } \\
\text { communal resources }\end{array}$ & $\begin{array}{l}\text { - Written communal resources in the } \\
\text { form of assessment tasks, and marking } \\
\text { systems. } \\
\text { - Understanding of these materials by } \\
\text { instructors is taken for granted by the } \\
\text { programme leader. }\end{array}$ & $\begin{array}{l}\text { - Written communal resources in the } \\
\text { form of assessment tasks, models, } \\
\text { and marking systems. } \\
\text { - Effort by the programme leader to } \\
\text { give in written (occasionally oral) } \\
\text { form information and knowledge to } \\
\text { understand variables. }\end{array}$ \\
\hline Mutual engagement & 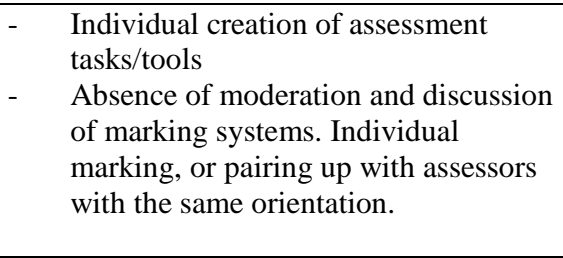 & $\begin{array}{ll}\text { - } & \text { Individual creation of assessment } \\
\text { tasks/tools } \\
\text { - }\end{array}$ \\
\hline
\end{tabular}

The instructors' and the programme leaders' assessment practices in these programmes cannot be explained by the theory of community of practice as predominantly understood, but by a community of interests-tainted practice. The power held by the programme leaders in the form of programme coordination and possession of 'expert' knowledge determined the knowledge to be taught and tested by the instructors as well as how, and with what aid. The programme leaders' interests and comfort zones determined the content tested in the assessment tasks, and controlled access of the instructors to this knowledge. The creation of both the assessment tasks and the marking systems was neither agreed on nor negotiated. The stakeholders in these programmes worked in disjointed rather than in jointed teams with concerted efforts. Different interpretations of the content knowledge for assessment of the laboratory report were apparent in Programme 1 especially. In Programme 2, the absence of multiple constructions of assessment processes can be accounted for given the tight control by the programme leader of the assessed genre of the laboratory report, as there was only one genre form/replica, the same one taught and assessed.

Further, despite being very few in occurrence, efforts by the programme leaders to establish common assessment understandings were restricted to written and transactional rather than oral or interactional strategies. With regards to communication and meetings, one-channel platforms (e.g., email) rather than face to face meetings or moderation sessions were used to agree on or standardize the assessment process amongst instructors. Such strategies were not enough for these TEFL instructors to acquire or learn the explicit knowledge that was clearly needed in the assessment of this scientific genre, let alone the transfer of tacit knowledge (Hunter \& Docherty, 2011; O’Donovan, Price \& Rust, 2004). Once again, socialisation of academic staff into disciplinary knowledge stood out as critical in promoting communities of assessment practice in these academic programmes (Price, 2005; Shay, 2008). Though rare in occurrence, the dialogues established by programme 2 leader with her instructors to discuss the content required for the assessment of the laboratory report were appreciated by the programme instructors. However, more is needed to establish communities of practice vis-a-vis the ones discussed in the literature.

To sum up, it is apparent that unlike the literature in support of community of practice (Wenger, 1998; but see Price, 2005) there was a strong fit between what Roberts (2006) described as impediment to thriving communities of practice and the assessment practices in both programmes in the 
sense that all instructors did "operate in an individualistic world of weak ties where resources are frequently obtained through personal networks and individual relationships rather than through organisational communities" (p. 635). A tentative characterisation of academic practices in higher education may proceed in the following manner: instead of community of practice, there are (sub)communities of practices wherein interaction, negotiation and communication amongst members and non-members are punctuated by control, power and autonomy, all working with the aim of narrowing the range between the personal goals of the academic and the communal goals of the institution. Theoretically, the question of whether the notion of a community of practice is applicable in these ESP programmes in questionable (See Nagy $\&$ Burch, 2009; Price, 2005), and perhaps notions of community of domination (Huzzard, 2004), community of (mal)practice (Pemberton, Mavin \& Stalker, 2007), and community of interests should be added.

\section{CONCLUSIONS}

In the current setting, little experience exists in promoting, supporting and managing communities of practice. Our current characterization of academe focuses on four differentiating factors: power relations, resources, incentives, and responsibilities. The present paper had the modest aim of examining the theory of community of practice in exploring the assessment practices in the academic writing of first year university students. Still, the research was able to document how power can hinder the facilitation of knowledge sharing amongst assessors in two academic programmes of study. It was apparent that power in the hands of the programme leaders determined the shape of knowledge to be included in the assessment tasks and the means and the methods of assessing that knowledge.

As a sense of community might have been readily available, our primary expectation was that language programmes with these content-specific curricula would form good places for establishing and developing communities of practice for two reasons. Firstly, because the TEFL instructors in this study exhibited wide general teaching experiences and limited specific domain teaching experience, it was expected that such variety would provide for the formation of communities of assessment practice and transfer of subject matter knowledge, where communication would be integral and critical. Secondly, in settings where these language programmes are run by programme coordinators, have planned and uniform curricula, and operate in multiple sections, in comparison to content programmes, where each is run autonomously by the content professor, have one planned and implemented curriculum, and operate in a single section it was expected that there would be greater opportunities for interaction and knowledge-sharing. However, on both planes the research study confirms otherwise.

The scant research in ESP (English for Special Purposes) in this area indicates that TEFL instructors are generally not secure with specific content (Belcher, 2006; Wu \& Badger, 2009). This may partially explain why there was no strong communication amongst these instructors, but this may also be attributable to the fact that the available power was not conducive to providing a safe environment where other knowledge and practices can be legitimated and accepted. This research raises questions about how assessment will fare in language education programmes which teach general English and have no specific emphasis on scientific content. As there is currently either little research investigating assessment from a community of practice perspective (Price, 2005), or that this framework was only examined generally and theoretically (Nagy \& Burch, 2009), there is a need to carry out more research in this area. As well, we can benefit from designing research which can more seriously look into the conditions which may facilitate or hinder the development of communities of practices in higher education.

\section{REFERENCES}

Barkaoui, K. (2011). Effects of marking method and rater experience on ESL essay scores and rater performance. Assessment in Education: Principles, policy \& practice, 18 (3), pp. 279293.

Belcher, D. D. (2006). English for specific purposes: Teaching to perceived needs and imagined futures in worlds of work, study and everyday life. TESOL Quarterly, 40(1), pp. 133-156.

Fox, S. (2000). Communities of practice, Foucault and actor network theory. Journal of Management Studies, 37(6), pp. 853-867.

Cox, A. (2005). What are communities of practice? A comparative review of four seminal works. Journal of Information Science, 31(6), pp. 527540.

Creswell J. W. (2009). Research design: Qualitative, quantitative, and mixed methods approaches. (3rd ed.). Thousand Oaks, CA: Sage Publications.

Denzin, N. K. (1989). The research act: $A$ theoretical introduction to sociological methods. (3rd ed.). Englewood Cliffs, NJ: Prentice Hall.

Handley, K., Sturdy, A., Fincham, R. \& Clark, T. (2006). Within and beyond communities of practice: Making sense of learning through participation, identity and practice. Journal of Management Studies, 43(3), pp. 641-653. 
Hunter, K. \& Docherty, P. (2011). Reducing variation in the assessment of student writing. Assessment \& Evaluation in Higher Education, 36(1), pp. 109-124.

Huzzard, T. (2004). Communities of domination? Reconceptualising organizational learning and power. The Journal of Workplace Learning, 16(6), pp. 350-361.

Kachru, B. B. (1997). Resources for research and teaching. In L. Smith (Ed.), World Englishes 2000 (pp. 209-251). Honolulu: University of Hawaii Press.

Lave, J. \& Wenger, E. (1991). Situated learning: Legitimate peripheral participation. Cambridge: Cambridge University Press.

Lincoln, Y. S., \& Guba, E. G. (1985). Naturalistic inquiry. Beverly Hills, CA: Sage.

Miles, M. B., \& Huberman, A. M. (1994). Qualitative data analysis: An expanded sourcebook. (2nd ed.). Sage publications: Thousand Oaks.

Nagy, J. \& Burch, T. (2009). Communities of practice in academe (CoP-iA): Understanding academic work practices to enable knowledge building capacities in corporate universities. Oxford Review of Education, 35(2), pp. 227247.

O’Donovan, B., Price, M. \& Rust, C. (2004). Know what I mean? Enhancing student understanding of assessment standards and criteria. Teaching in Higher Education, 9(3), pp. 325-335.

Pemberton, J., Mavin, S. \& Stalker, B. (2007). Scratching beneath the surface of communities of (mal)practice. The Learning Organization: The International Journal of Knowledge and Organizational Learning Management, 14(1), pp. 62-73.
Price, M. (2005). Assessment standards: The role of communities of practice and the scholarship of assessment. Assessment and Evaluation in Higher Education, 30(3), pp. 215-230.

Price, M., Carroll, J., O’Donovan, B. \& Rust, C. (2011). If I was going there I wouldn't start from here: A critical commentary on current assessment practice. Assessment \& Evaluation in Higher Education, 36(4), pp. 479-492.

Roberts, J. (2006). Limits to communities of practice. Journal of Management Studies, 43(3), pp. 623-639.

Shay, S. (2008). Beyond social constructivist perspectives on assessment: the centring of knowledge. Teaching in Higher Education, 13(5), pp. 595-605.

Wenger, E. (1998). Communities of practice: Learning, meaning and identity. Cambridge: Cambridge University Press.

Wenger, E. (2000). Communities of practice and social learning systems. Organization, 7(2), pp. 225-246.

Wenger, E., McDermott, R., \& Snyder, W. M. (2002). Cultivating communities of practice. Boston, MASS, Harvard Business School Press.

Wu, H., \& Badger, R. (2009). In a strange and uncharted land: ESP teachers' strategies for dealing with unpredicted problems in subject knowledge during class. English for Specific Purposes, 28(1), pp. 19-32.

\footnotetext{
${ }^{1}$ Because of skewed distribution in the number of teaching experience overall the mean is not used because the median is more informative here.
} 